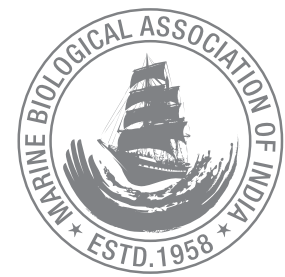

\title{
Reproductive dysfunction in the edible oyster, Crassostrea madrasensis due to larval bucephalid infection - a case study
}

\author{
G. Suja*, N. K. Sanil, S. Chinnadurai, and K. K. Vijayan \\ Central Marine Fisheries Research Institute, PB No. 1603, Cochin - 682018, India. \\ *Correspondence e-mail: sujagangadhar@gmail.com
}

Received: 25 Oct 2013, Accepted: 15 Jan 2014, Published: 30 Jan 2014

Original Article

\begin{abstract}
The present case study provides an insight into the tissue level pathological alterations inflicted by Bucephalus sp. infections in the edible oyster, Crassostrea madrasensis. Oysters collected during a routine study (from the oyster beds along the Southeast coast of India during July 2012) was found to harbor larval bucephalid infection. Though the prevalence of infection was low $(1.37 \%)$, the intensity of infection was high, rated as two on the semi-quantitative scale. Infected oyster did not exhibit any external manifestation, but the developing parasitic stages, after replacing the host gonadal tissues have further spread to the gills and digestive glands. Regions of gonadal tissues were found packed with slender, branching sporocysts containing germ balls and crecariae, destroying the acinar architecture of the gonads. Immune responses like encapsulation against the infective stages were totally absent. The altered acinar architecture and reduced volume of the gonadal acini appeared to be insufficient to support any gametic release, resulting in gonadal dysfunction leading to parasitic castration of the host. An increase in the prevalence of Bucephalus sp. infection in the ecosystem could seriously hamper the reproductive potential of the wild stocks of oysters, thereby affecting the viability of oyster farming in the region.
\end{abstract}

Keywords: Indian backwater oyster, parasite, trematode, histopathology, sporocyst, parasitic castration.

\section{Introduction}

Marine bivalves can harbor an array of parasites and pathogens capable of causing mortalities leading to economic losses, especially in farmed species (Bower et al., 1994). Hostparasitic interactions leading to host mortality, morbidity, reduced growth and reproduction gains much importance in case of commercially cultured species as it reflects in economic terms (da Silva et al., 2002). Infections with protozoans like Bonamia spp. and Perkinsus spp. serve as some of the typical examples for high mortalities in oyster populations (Grizel et al., 1988; Sanil et al., 2010). Many metazoan parasites, including larval trematodes are also known to cause serious health issues in bivalve populations. Digenetic trematodes using bivalves as intermediate hosts have been widely reported (Shelley et al., 1988; Lasiak, 1993; Winstead et al., 2004). Various commercially exploited bivalves such as mussels (Lasiak, 1993; da Silva et al., 2002); oysters (Winstead et al., 2004) and clams (Taskinen, 1998; Vazquez et al., 2006) have been reported to harbor larval trematode infections resulting in the impairment of reproductive capacity leading to host castration.

Most digenetic trematodes use gastropods as their primary intermediate hosts but trematodes of the families 
Gymnophalidae, Fellodistomidae and Bucephalidae are known to select bivalves as their primary or secondary (or both) intermediate hosts. The final or definitive host may be a carnivorous fish as in the case of Fellodistomidae and Bucephalidae (Sindermann and Rosenfield, 1967; Kim et al., 2006) or aquatic birds as in the case of Gymnophalidae (Mladineo and Peharda, 2005). Asexually reproducing stages in the trematode life cycle such as sporocysts/redia develop in the bivalve host, often with low prevalence. Host immune responses are limited when they are found in their natural intramolluscan habitats because both the parasite and host are well adapted to each other (Cremonte et al., 2005). Larval trematode parasitism, even at low prevalence gains much importance due to the severe damage inflicted to gonadal tissues in infected individuals.

The edible oyster, Crassostrea madrasensis, also known as the Indian backwater oyster is the most dominant oyster species, occurring in the estuaries, bays and backwaters along the southeast and southwest coasts of India. C. madrasensis attains a maximum size of $22 \mathrm{~cm}$, has an average life span of 3-4 years; young oysters up to $78 \mathrm{~mm}$ size of zero year group were observed to be functional males and $72 \%$ of the population of one year old and above $(118.5 \mathrm{~mm}$ ) were females (Narasimham and Kripa, 2007). The successful hatchery breeding and seed production have made this a candidate bivalve species which contributes about $\mathbf{4 0 0 0}$ tones to the fast growing bivalve farming sector in India. The rapidly expanding edible oyster farming and its management points to the importance of information on the parasites/pathogens of this species which is presently very limited (Samuel, 1978; Sanil et al., 2012). Larval stages of the trematode, Bucephalus sp., have been reported in C. madrasensisby Joseph (1978) and Palaniswamy (1993) while Samuel (1978) has identified the trematode as Bucephalopsis haimeanus from Tuticorin. Though many reports exist on the larval bucephalid infections in bivalves including those from Indian waters, histopathological studies to elucidate the effects of parasitism on the gonadal tissues leading to organ dysfunction/castration are not available from tropical waters. The present case study elucidates the pathological and physiological changes leading to reproductive dysfunction in C. madrasensis during Bucephalus sp. infections.

\section{Material and methods}

\section{Sampling and area of study}

Samples of C. madrasensis were collected in January, July and November 2012 from the oyster beds of Karapad $\left(08^{\circ} 46^{\prime} 53.89^{\prime \prime} \mathrm{N}\right.$ and $\left.78^{\circ} 09^{\prime} 36.00^{\prime \prime} \mathrm{E}\right)$ in Tuticorin Bay, along the southeast coast of India. A total of 73 samples measuring $66-146 \mathrm{~mm}$ in length were collected (January $\mathrm{N}=20$, July
$\mathrm{N}=30$ and November $\mathrm{N}=23$ ). Samples were brought to the laboratory and morphometric data like, shell length (dorsoventral) in $\mathrm{mm}(\mathrm{SL})$, shell height (anterio - posterior) in $\mathrm{mm}(\mathrm{SH})$ and shell width in $\mathrm{mm}(\mathrm{SW})$ were measured by a digimatic caliper (Mitutoyo Cor, Kawasaki, Japan) and total weight (TWt) (g) tissue weight (TiWt) (g) and shell weight (SWt) $(\mathrm{g})$ were taken using a chemical balance. Condition index was calculated using the formula, $\mathrm{Cl}=\mathrm{Ti} \mathrm{Wt} /(\mathrm{SL}) \times(\mathrm{SH})$ $x$ (SW) x1000 (Choi and Chang, 2003).

Samples were shucked and examined for gross macroscopic abnormalities. Parameters like general appearance, fouling, shell damage, gaping, retraction of mantle, wateriness of the tissues, abnormal coloration, presence of abscess, lesions, pustules, tissue discoloration etc. were considered while assessing the condition of the oysters. Samples were dissected under a stereomicroscope and squash preparations taken from mantle, gonads, digestive tubules and gills were examined using a research microscope (Nikon, Eclipse 80i, Japan). Sex determination of each specimen was carried out either through smear from the gonadal region or through histological slide observation.

\section{Histopathology}

A transverse section of $5 \mathrm{~mm}$ (including gills, mantle and visceral mass) was made and fixed in Davidson's fixative (Shaw and Battle, 1957) for 24-48 hours, and processed following standard histological procedures like dehydration in ethanol series, clarified in xylene and embedded in paraffin. Sections were taken (5-6 $\mu \mathrm{m}$ thickness) using a Leica Microtome (Leica, Wetzlar, Germany) and stained with Harris Hematoxylin and Eosin (H\&E). Sections were examined under light microscopy and the intensity of infection was rated according to Kim et al., (2006). The rating was based on a semi-quantitative scale with four classes to rate the infection; $0=$ Uninfected; $1=$ Present in the gonads only (gametic tissue still present), 2 = Completely filling the gonads (traces/no gametic tissue present), may be present in digestive gland or gills in very limited amount; 3 = Completely filling the gonads, extensive invasion of digestive gland and/or gills; $4=$ Completely filling the gonad, substantially filling the digestive gland or gill and individuals may appear as a sac of sporocysts.

\section{Results}

\section{Prevalence}

Samples of Crassostrea madrasensis collected during January and November were negative; but, the July sample showed a single case of larval trematode infection (1 out of 73 , prevalence of $1.37 \%$ ). The infected animal did not exhibit any apparent external manifestations; but squash preparation revealed the presence of sporocysts and pear- 


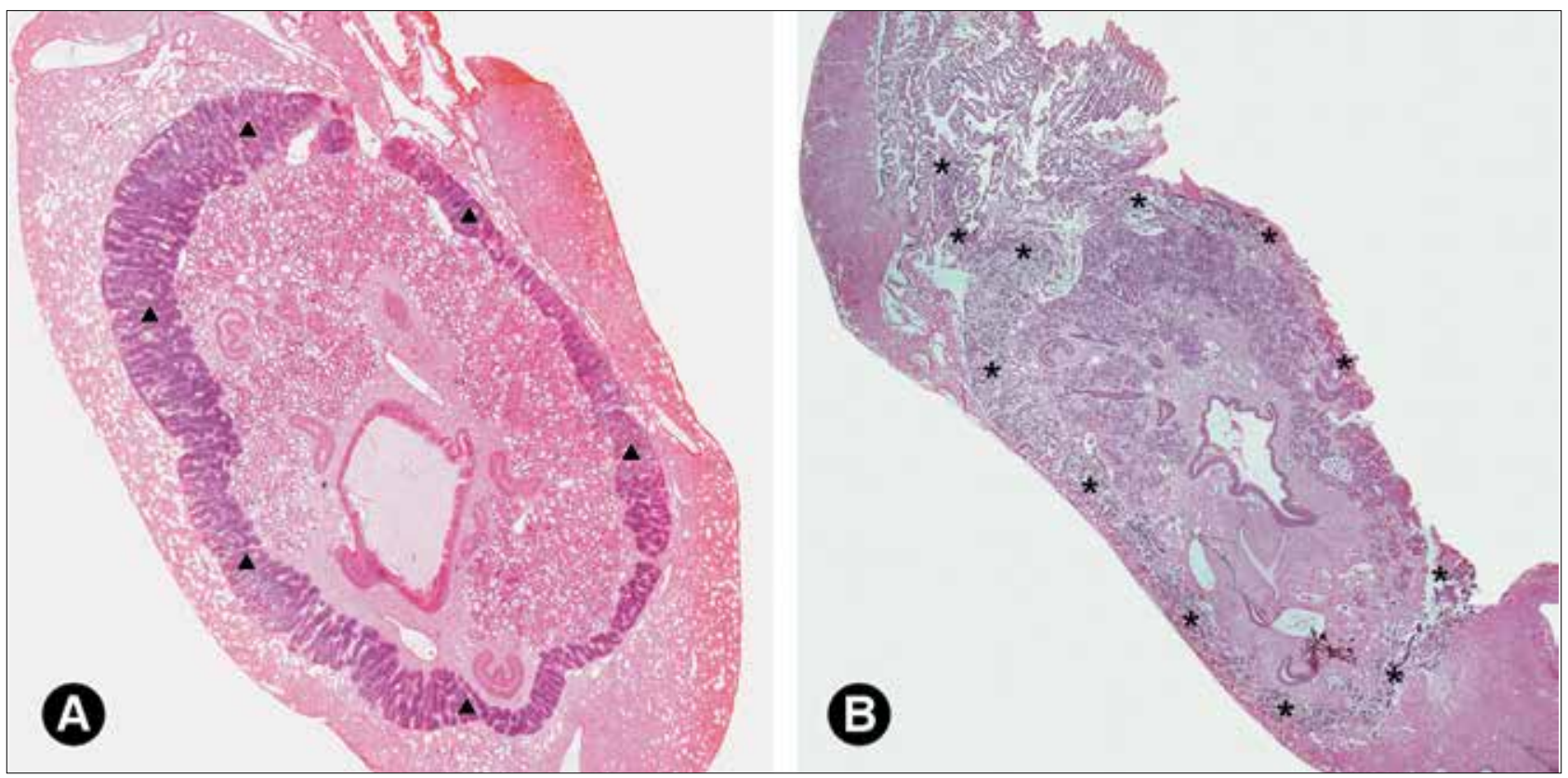

Fig. 1. Reconstructed image of the transverse sections of $C$. madrasensis. A. Uninfected male with darkly stained, mature gonads (Triangle: mature male gonads). B. Infected male with the developmental stages of Bucephalus sp., completely replacing the gonadal tissues (Asterix: developmental stages of the parasite). (H\&E staining).

shaped, gasterostome cercariae having a short tail with two characteristic long, slender furcae indicating Bucephalus sp. infection in the tissues. Condition index value of the samples ranged from 0.031 to 0.065 , with an average of 0.05 , while the $\mathrm{Cl}$ value of the infected sample was 0.034 .

\section{Histopathology}

Detailed histopathological evaluation of the infected specimen showed severe alterations in gonadal tissues, compared to uninfected ones. Based on these observations, the intensity of infection was rated as 2 on the semi-quantitative scale as suggested by Kim et al. (2006). Uninfected C. madrasensis had fully mature gonads surrounding the digestive system (Fig.1A), while in the infected oyster, the gonadal tissues were filled with larval stages of the parasite (Fig.1B).The entire gonadal tissues were replaced by the developmental stages of the parasite and the region between the mantle and digestive tubules were found packed with slender, branching sporocysts (Fig 2A, 2B). Each sporocyst contained numerous germballs and crecariae at different stages of maturity (Fig.2C, 2D). The multi-branched, filamentous structure of the sporocyst and the pear-shaped, gasterostome cercariae having a short tail with two characteristic long, slender furcae indicated the affiliation of the parasite to the genus Bucephalus (Von Baer, 1827). Since species level identification of trematodes cannot be done based on the morphological characteristics of the larval stages alone, the parasite is referred to as a bucephalid in the paper. In uninfected oysters, the gonadal tissues consisted of large number of well organized, developing gametogenic

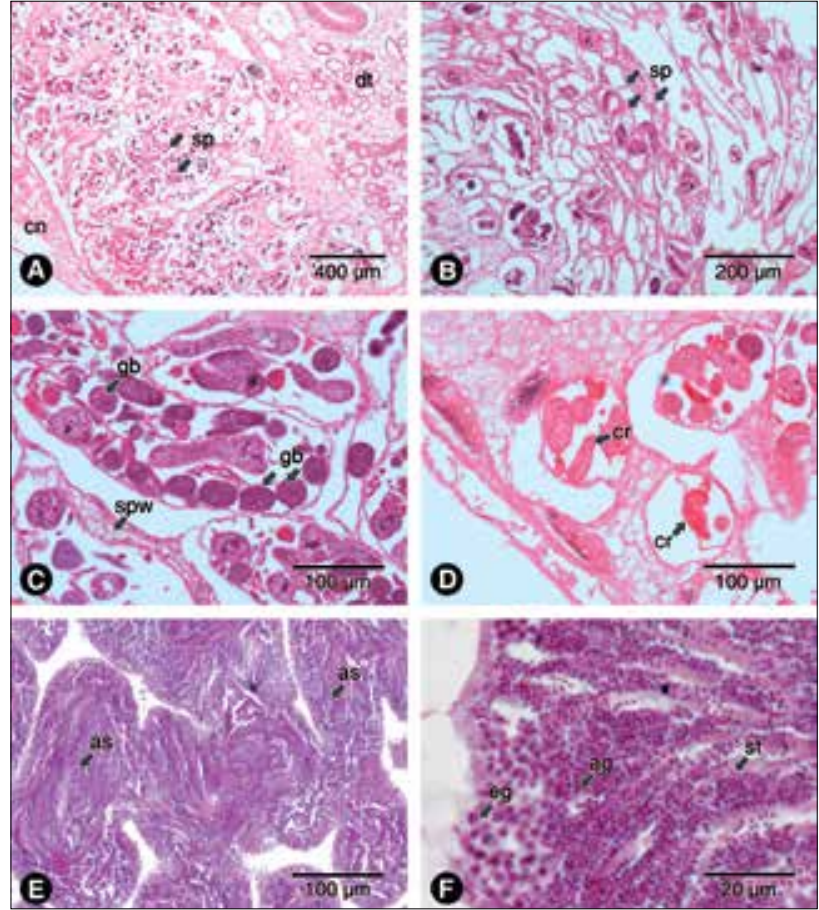

Fig. 2. Histopathology of uninfected and infected C. madrasensis with larval bucephalid infection. A. Developing mass of sporocysts in the gonadal region. B. Highly branching sporocysts in the connective tissues. C. Sporocysts with developing germ balls. D. Bucephalid cercariae with slender furcae within sporocysts. E. Uninfected male gonads with fully developed gametogenic acini. F. Magnified view of acini showing early germ cell line to the periphery and advanced germ cells and spermatids with tail towards lumen. Abbreviations: ag: advanced germ cell line; as: acinus; cn, connective tissue; cr: cercaria; dt: digestive tubules; eg: early germ cell line; gb: germball; sp: sporocyst; spw: sporocyst wall; st: sperm with tail. (H\&E staining). 
acini with follicles densely packed with spermatozoa (Fig. 2E). The outer or basal region of the acini consisted of early germ cell line which includes spermatogonia, spermatocytes and undifferentiated, round spermatids and the lumen of the acini contained elongated spermatids with tails oriented towards the center of the lumen (Fig. 2F). In infected C. madrasensis, the characteristic acinar architecture was destroyed. The number and area of gametogenic acini have been reduced drastically

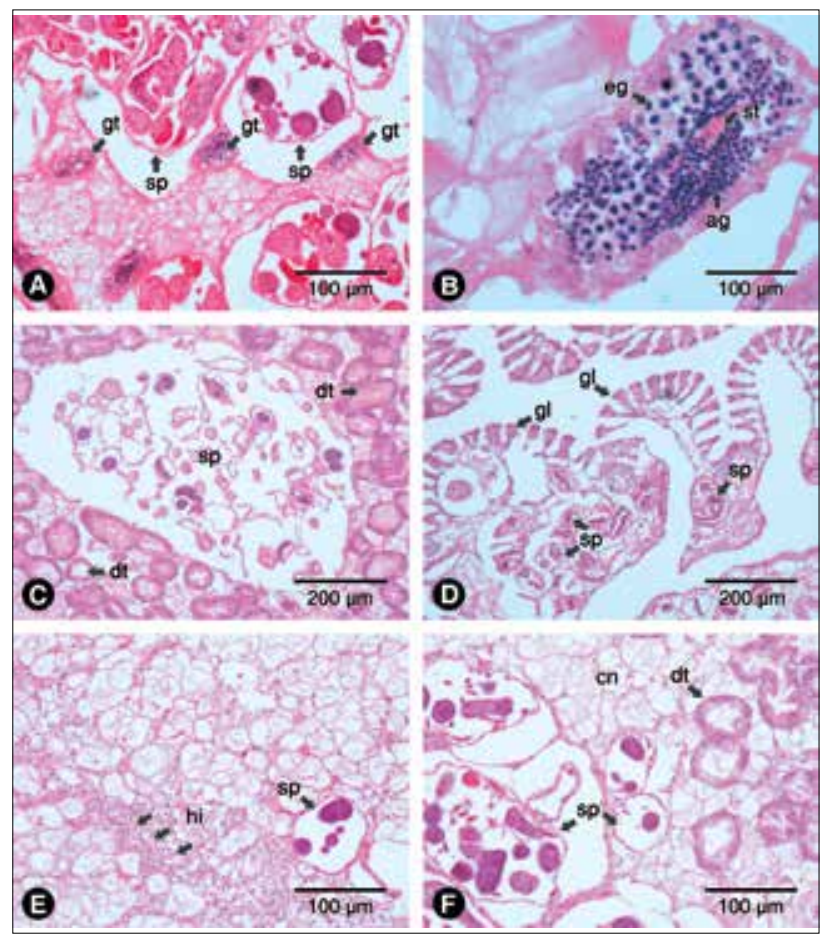

Fig.3. Histopathology of C. madrasensis with larval bucephalid infection. A. Small patches of gonadal tissue adjacent to developing sporocyst mass. B. magnified view of a patch of gonadal tissue showing reduced number of early and advanced germ cell lines and spermatids. C. Sporocysts between the digestive tubules. D. Sporocysts in the gills. E. Hemocytic infiltration near a developing sporocyst. F. Sporocysts in the connective tissue near digestive tubules without eliciting any host reaction. Abbreviations: ag: advanced germ cell line; cn, connective tissue; dt: digestive tubules; eg: early germ cell line; gl: gills; gt: gonadal tissue; hi: hemocytic infiltration; sp: sporocyst; st: sperm with tail. (H\&E staining).

and the remnants of the gonads were represented by small, irregular patches of gonadal tissues distributed along the edges or interspersed within the developing sporocyst masses (Fig.3A). Within these patches of gonadal tissues, the process of gametogenesis appears to be continuing as evidenced by the presence of spermatogonial cells, spermatocytes and spermatids, though very less in number (Fig.3B), but a well-defined lumen and gonoducts were absent. The drastic reduction in the number and area of gonadal acini and the altered acinar architecture revealed the damage inflicted by the parasite to the gonadal tissues in infected oysters. A few sporocysts were also observed in the digestive gland and gill tissues indicating that the infection is spreading towards other organs (Fig 3C, 3D).

Immune responses against the parasitic stages were almost absent except for very low levels of hemocytic infiltration observed in the connective tissues adjacent to sporocysts in some regions (Fig.3E). Other immune responses like inflammation and encapsulation of the parasites/stages by hemocytes were totally absent (Fig 3F).

\section{Discussion}

Generally, the pattern of larval trematode infections in bivalves shows low prevalence and high intensity. The prevalence of bucephalid infection in the present study was quite low at $1.37 \%$, which is in agreement with most of the earlier studies (Samuel, 1978; Palaniswamy, 1993; da Silva et al., 2002; Winstead et al., 2004). Larval trematode infections in mussels are usually manifested as orange to bright red, filiform, sporocyst mass (Lasiak, 1993), while in the present case the infected oyster did not exhibit any colouration or external abnormalities. Winstead et al., 2004 have also observed that even heavily infected oysters did not exhibit any external manifestations.

Different stages of bucephalids are known to cause varied pathological changes depending on the site of infection (Mladineo and Peharda, 2005) and host species involved (Cremonte et al, 2005). In healthy, uninfected C. madrasensis, mature gonads consist of large number of functional gametogenic acini with spermatogonia, spermatocytes and undifferentiated, round spermatids while the lumen was packed with elongated spermatids. In the infected oyster, the presence of numerous germballs and crecariae at different stages of maturity within the sporocysts indicate the developmental potential of the infection which is in an active stage and has started spreading over to the digestive gland and gills. In the present study the sporocyst mass has already invaded and replaced the gonadal tissues while the process of invasion in the digestive and gill tissues have just started as evidenced by the fewer sporocyst masses in them. It appears that the gonads act as the primary site of infection for larval bucephalids in C. madrasensis, which was in contradiction to the observations of Cheng and Burton (1965) in C. virginica, where the primary site of bucephalid infection was digestive glands. The parasite can afford to enjoy a prolonged period of development in gonads because damage to gonads may not directly affect the health of the host. However, the spreading of the infection into vital organs like digestive tissues may physiologically weaken the host, affecting its health as evidenced by the lower $\mathrm{Cl}$ value when compared 
to the group mean. As Cheng and Burton (1965) have pointed out, the preference of primary site of infection may vary between different species/hosts or may be dependent on the physiological state of the particular organ. In the case of infected C. madrasensis, the period of infection coincides with the second peak spawning season (July - September) for $C$. madrasensis in the region and during the spawning season, the soft and nutrient rich gonadal tissues will be highly conducive for the developing larval stages (Cheng and Burton, 1965). Taskinen et al. (1997) while discussing Rhipidocotyle infections in Anodonta piscinalis have also observed that parasites adjust their time of reproduction with periods when the hosts have high nutrient resource/reserve levels, so that the risk of host mortality is minimised.

Generally in larval trematode infections, sporocysts induce marked pathological manifestations like severe tissue destruction, retardation of gametogenesis leading to castration and necrosis of connective tissue (Mladineo, 2008; Ceuta and Boehs, 2012). Several authors have suggested that gonadal damage by larval trematodes could be caused by physical/mechanical (ingestion, abrasion and sporocyst pressure) or chemical (secretion of lytic substances, toxins, or endocrinological antagonists) mechanisms (Oliva, 1992; Bower et al., 1994; Boehs et al., 2010). Shelly et al. (1988) have reported the breakdown of normal gonadal architecture and hypertrophy following bucephalid infections in Tridacna crocea. Parasitic castrations caused by larval trematode infections have been reported in many bivalve species (Khamdan, 1998; Winstead et al., 2004; Mladineo, 2008; Darriba et al., 2010). Many authors have also reported altered physiological states associated with larval trematode infections leading to unusual fast growth/gigantism in snails and oysters, progressing through castration and finally leading to mortality when vital organs are affected (Cheng and Burton, 1965; Taskinen, 1998).

Immune responses of bivalves infected with larval trematodes varies with the infection site and in many cases, normal immune responses like encapsulation may fail to occur in their natural intra-molluscan hosts (Cremonte et al., 2005; Mladineo and Peharda, 2005; Vazquez et al., 2006). In the present case, a low level of hemocyte infiltration was observed in some regions, but any form of encapsulation was not observed. Villalba et al. (1997) have reported heavy inflammatory response including granulocytomas in Mytilus galloprovincialis against the larval stages of the trematode, Proctoeces maculatus leading to the encapsulation and destruction of the parasite. Cheng and Burton (1965) have observed that larval Bucephalus sp. infections did not elicit any encapsulation reaction in C. virginica. Ceuta and Boehs (2012) suggest lack of host response as a feature of Bucephalus infections. In the present case also, immune responses were totally absent indicating the ability of the parasite to evade or silence the hosts' immune mechanisms. The feeble hemocyte infiltration observed in some regions could be attributed to host tissue injury rather than to any specific response elicited by the parasite as suggested by da Silva et al. (2002) while discussing the effects of Bucephalus sp. on $P$. perna in Brazil. The lack of any effective immune response indicates that the bivalve host never gets rid of the infection, continues to produce infective cercarial stages, contributing to the successful completion of the trematode life-cycle and compensating for the low prevalence generally observed in larval Bucephalid infections (Taskinen et al., 1997).

The massive replacement of gonadal tissues with sporocyst mass leaving only the remnants of gonadal tissues in small patches in the present study indicates the severity of damage caused by the parasite. The presence of spermatogonial cells, spermatocytes and spermatids, though in very limited numbers, indicate that the process of gametogenesis is still being carried out in these gonadal patches. But the altered tissue architecture as evidenced by the absence of typical acinar lumen and gonoducts and the drastic reduction in the number and volume of the gonadal acini appears to be insufficient to support any gametic release, resulting in gonadal dysfunction leading to parasitic castration of the host. Probably, as the infection progresses, these remaining gonadal tissues will also be replaced or resorbed leading to the total absence of gonadal tissues in the host.

In closed water bodies or similar estuarine systems where the intermediate and definitive fish hosts of Bucephalus sp. are present in large numbers, the transmission potential can increase, leading to a buildup of bucephalid infection in the system. Though hatchery techniques for the larval production of $C$. madrasensis exist, availability of spat remains a major problem and majority of the farmers still depend on the wild collected spat. An increase in the prevalence of Bucephalus infection in the ecosystem can seriously hamper the reproductive potential of the wild stocks and thereby limit the availability of the spat, affecting the viability of oyster farming in the region.

\section{Acknowledgements}

We extend our gratitude to the Director, CMFRI, Cochin for providing the facilities for conducting the study. We are also indebted to K.K. Surendran and P. Shamal from the Marine Biotechnology Division and Jenny Sharma, Mathew Joseph and P. S. Alloycious from the Molluscan Fisheries Division for their assistance during sample collection and processing. The authors are also grateful to the National Agricultural 
Innovation Project (NAIP) - "A value chain on high value shell fish from mariculture systems" for the financial support.

\section{References}

Boehs, G., A. Villalba, L.O. Ceuta and J.R. Luz. 2010. Parasites of three commercially exploited bivalve mollusc species of the estuarine region of the Cachoeira River (Ilheus, Bahia, Brazil). J. Invertebr. Pathol., 103: 43-47.

Bower, S.M., S.E. McGladdery and I.M. Price. 1994. Synopsis of infectious diseases and parasites of commercially exploited shellfish. Annu. Rev. Fish Dis., 4:1-199.

Ceuta, L.O. and G. Boehs. 2012. Parasites of mangrove mussel Mytella guyanensis (Bivalvia: Mytilidae) of Camamu Bay, Bahia, Brazil. Braz. J. Biol., 72(3): 421-427.

Cheng, T.C. and R.W. Burton. 1965. Relationships between Bucephalus sp. and Crassostrea virginica: histopathology and sites of infection. Chesapeake Sci.. 6: 3-16.

Choi, Y.H. and Y.J. Chang. 2003. Gametogenic cycle of the transplanted -cultured pearl oyster, Pinctada fucata martensii (Bivalvia: Pteriidae) in Korea. Aquaculture, 220: 781-790.

Cremonte, F., A. Figueras and E.M. Burreson. 2005. A histopathological survey of some commercially exploited bivalve molluscs in northern Patagonia, Argentina. Aquaculture, 249: 23-33.

Da Silva, P.M., A.R.M. Magalhaes and M.A. Barracco. 2002. Effects of Bucephalus sp. (Trematoda: Bucephalidae) on Perna perna mussels from a culture station in Ratones Grande Island, Brazil. J. Invertebr. Pathol., 79: 154-162.

Darriba, S., D. Iglesias, M. Ruiz, R. Rodriguez and C. López. 2010. Histological survey of symbionts and other conditions in razor clam Ensis arcuatus (Jeffreys, 1865) (Pharidae) of the coast of Galicia (NW Spain). J. Invertebr. Pathol., 104: 23-30.

Grizel, H., E. Mialhe, D. Chagot, V. Boulo and E. Bach Ere. 1988. Bonamiosis: a model study of diseases in marine molluscs. Am. Fish. Soc. Spec. Publ., 18: 1-4.

Joseph, M.M. 1978. Observations on the larval trematode Bucephalus sp. parasitie in the oyster Crassostrea madrasensis. J. Invertebr. Pathol., 32: 381-383.

Khamdan, S.A.A. 1998. Occurrence of Bucephalus sp. trematode in the gonad of the pearl oyster Pinctada radiata. Envir. Int., 24 (1-2): 117-120.

Kim, Y. and E.N. Powell. 2006. Relationships among parasites and pathologies in sentinel bivalves: NOAA Status and Trends 'Mussel Watch' Program. Bull. Mar. Sci., 79:83-111

Kim,Y., E.N. Powell and K.A. Ashton-Alcox. 2006. Histopathology analysis. In: Y. Kim, K.A. Ashton-Alcox and E.N. Powell, (Eds.) Histological techniques for marine bivalve molluscs: Update NOAA Tech. Mem. NOS NCCOS, 27:19-52.

Lasiak, T.A. 1993. Bucephalid trematode infections in the brown mussel Perna perna (Bivalvia: Mytilidae). S. Afr. J. Mar. Sci, 13(1): 127-134

Mladineo, I. 2008. Risk assessment of parasitic/symbiotic organisms of the commercially important mytilid Modiolus barbatus (Linnaeus, 1758). Aquac. Res., 39: 17051719.
Mladineo, I. and M. Peharda. 2005. Histopathology of Gymnophallus sp. sporocysts in the edible mytilid, Modiolus barbatus. J. Shellfish Res., 24: 1097-1100.

Narasimham, K.A. and V. Kripa. 2007. Textbook of oyster biology and culture in India. Indian Council of Agricultural Research, New Delhi. 233p.

Olivia, M.E. 1992. Parasitic castration in Fissurella crassa (Archaeogastopoda) due to an adult digenea, Proctoeces lintoni (Fellostomidae). Mem. Inst. Oswaldo Cruz, Rio de Janeiro, 87(1): 37-42.

Palaniswamy, R. 1993. Seasonal gonadal changes, spawning and condition index of oyster Crassostrea madrasensis (Preston) in the Korampallam creek, Tuticorin. Indian J. Fish., 40(4): 242-246.

Samuel, D. 1978. A digenetic trematode infection in the edible oyster Crassostrea madrasensis (Preston). Indian J. Fish., 23(1\&2): 153-159.

Sanil, N.K., K.K. Vijayan, V. Kripa and K.S. Mohamed. 2010. Occurrence of the protozoan parasite, Perkinsus olseni in the wild and farmed Pearl Oyster, Pinctada fucata (Gould) from the Southeast coast of India. Aquaculture, 299: 8-14.

Sanil, N.K., G. Suja, J. Lijo and K.K. Vijayan. 2012. First report of Perkinsus beihaiensis in Crassostrea madrasensis from the Indian subcontinent. Dis. Aquat. Org., 98: 209-220.

Shaw, B.L. and H.I. Battle. 1957. The gross and microscopic anatomy of the digestive tract of the oyster Crassostrea virginica (Gmelin). Can. J. Zool., 35:325-347.

Shelley, C.C., J.S. Glazebrook, E. Turak, L. Winsor and G.R.W. Denton. 1988. Trematode (Digenea: Bucephalidae) infection in the burrowing clam Tridacna crocea from the Great Barrier Reef. Dis. Aquat. Org., 4: 143-147.

Sindermann, C. J. and A. Rosenfield. 1967. Principal diseases of commercially important marine bivalve Mollusca and Crustacea. Fish. Bull. (Washington, DC), 66: 335-385.

Taskinen, J. 1998. Influence of trematode parasitism on the growth of a bivalve host in the field. Int. J. Parasitol., 28: 599-602.

Taskinen, J., T. Makela and E.T. Valtonen. 1997. Exploitation of Anodonta piscinalis (Bivalvia) by trematodes: parasite tactics and host longevity. Ann. Zool. Fennici, 34: 37-46.

Thangavelu, R. and P.J. Sanjeevaraj. 1987. Host-parasite relation between Bucephalopsis haemeanas and Crassostrea madrasensis in the Pulicat Lake. J. Mar. Biol. Ass. India, 29 (1): 220-225.

Vázquez, N.N., C. Ituarte, G.T. Navone and F. Cremonte. 2006. Parasites of the stout razor clam Tagelus plebeius (Psammobiidae) on the Argentinean coast, Southwest Atlantic Ocean. J. Shellfish Res., 25: 877-886.

Villalba, A., S.G. Mourelle, M.J. Carballal and C. Lo'Pez. 1997. Symbionts and diseases of farmed mussels Mytilus galloprovincialis throughout the culture process in the Rias of Galicia (NW Spain). Dis. Aquat. Org., 31: 127-139.

Winstead, J. T., A.K. Volety and S.G. Tolley. 2004. Parasitic and symbiotic fauna in oyster (Crassostrea virginica) collected from the Caloosahatchee River and Estuary in Florida. J. Shellfish Res., 23: 831-840. 